\title{
Patricio Núñez
}

\author{
Jorge Hidalgo $^{1}$
}

\begin{abstract}
$\mathrm{Al}$ abrir el libro de mis recuerdos hay un esbozo de capítulo en torno a un amigo, Patricio Núñez, admirable de muchas maneras. Patricio fue una persona que se distinguía en cualquier parte, desde joven, por su sentido del humor, su habla con cierta tartamudez, su manera de vestir no convencional que recordaba algunos rasgos del hipismo de los años sesenta del siglo pasado. Lo conocí en esa etapa, siendo ambos estudiantes de historia en el Instituto Pedagógico de la Universidad de Chile. En el país y en esa casa de estudios eran años aun de formalidad en el vestir. El uso de la corbata y chaqueta era parte de ese código que imponían las costumbres. Además, los zapatos debían estar bien lustrados y por cierto la camisa en su parte inferior debía quedar bajo el pantalón. Mi recuerdo de Patricio no coincide con esa imagen. Usaba condoritos o hawaianas de plástico como calzado, vestía con pantalones cortos y camisa ancha que caía libremente, de mangas cortas, pues Patricio fue siempre acalorado. Un par de años después se agregó una larga cabellera liza que caía sobre su espalda y como contraste una frondosa barba negra. Alguna chuspa colgaba de su hombro poniendo de manifiesto su elección por lo andino como su tema de estudio. Era evidente que su sola presencia marcaba la originalidad de un destino elegido al margen de las convenciones.
\end{abstract}

Era una persona con una franqueza y valentía fuera de lo común, junto con una gran calma y paz interna. Fue un hombre sin dobleces, generoso y de gran rectitud. Recuerdo que por esos años que usaba el pelo largo, me contó que unos sujetos le habían dicho algunas frases que sonaban a piropos dirigidos a una mujer. Patricio retrocedió y les dijo "si a la edad de ustedes no saben distinguir a un hombre de una mujer lo lamento por ustedes, pues deben haber tenido momentos muy buenos y otros muy malos". Los dejó perplejos y sin réplica. La verdad es que, si uno no hubiera conocido su bondad, su apariencia parecería amenazante. Pues fue siempre un hombre robusto.
Tempranamente excavó como arqueólogo en diversos lugares de Tarapacá. Recuerdo su admiración por sitios prehispánicos que trabajó en Huatacondo, así como la aldea de Tarapacá Viejo que pensó como de la colonia hispana. Al poner esa hipótesis en ese campo estimuló posteriores investigaciones de otros equipos científicos que establecieron un origen más cercano a los Incas, lo que no niega su etapa como centro de la encomienda de Lucas Martínez Vegaso.

Un día, todavía en Santiago, me contó que se iría permanentemente al norte para trabajar con Lautaro Núñez, quien estaba sufriendo dolencias en sus manos, lo que eventualmente le impediría excavar. Me dijo "voy a ser las manos de Lautaro". Frase que expresaba su admiración por el talento arqueológico de Lautaro, su afecto por el amigo y también su propia humildad. En efecto se fue a trabajar a la sede de la Universidad de Chile en Antofagasta, donde trabajó hasta su jubilación.

En esos años escribió artículos y libros en que difundió, ante la comunidad científica y personas interesadas, sus investigaciones en el desierto, a las que agregaba sus reflexiones ensayando muy diversas miradas. Manteníamos correspondencia y compartió conmigo sus hallazgos y el uso de los métodos en que intentaba dialogar resultados que yo había alcanzado en mis propias investigaciones. Por ejemplo, se esforzó por calcular, a partir de las superficies y técnicas empleadas en los cultivos agrícolas, la dimensión demografía de esas poblaciones prehispánicas que habitaron esos territorios. Así como analizaba problemas de producción económica y demografía también se preocupaba de valorar las expresiones artísticas de esas poblaciones. Su curiosidad científica no tenía límites. En sus últimos años se dedicó a escribir temas históricos e incluso de género. Su perspectiva era profundamente feminista. Esta variedad de temas en sus estudios permite considerar a Patricio como un polígrafo.

Patricio tuvo dos hijos, Carolina y Rodrigo, con su primera esposa Inger. Años más tarde inició una

\footnotetext{
${ }^{1}$ Profesor Titular, Departamento de Ciencias Históricas, Facultad de Filosofía y Humanidades, Universidad de Chile. hidalgol@uchile.cl
} 
relación con Adriana Sáez, Bibliotecaria del Centro Nacional de Conservación de la DIBAM. Ella lo acompañó en sus últimas décadas con una notable mutua dedicación en una relación que fue muy positiva para ambos. Fueron una hermosa pareja.

De un modo diferente no se puede olvidar en el entorno de Patricio a su compañero de trabajo y entrañable amigo Eduardo Muñoz. Eduardo formado en la Escuela de Canteros fundada en la Universidad de Chile por el mítico escultor Samuel Román, derivó a un trabajo sistemático de conservación de sitios patrimoniales. Eduardo junto con Mónica Bahamondez y Patricio hicieron equipo en numerosos proyectos. Mónica me cuenta una anécdota de sus amigos. Regresaban ambos a la costa desde un lejano sitio altiplánico cuando el Jeep que manejaba Eduardo sufrió una avería que detuvo el vehículo. Eduardo bajó a ver que se podía hacer y descubrió que el daño era irreparable y se encontraban los dos solos, en un camino poco transitado, cuando avanzaba la noche y descendía la temperatura a niveles peligrosos. Volvió a la cabina y le preguntó a Patricio con voz desesperada ¿qué hacemos? Patricio con su calma inefable respondió ¡Comámonos un sándwich! Fue lo que hicieron con calma, Eduardo algo nervioso y Patricio tranquilo. Cuando finalizaron un camionero boliviano que bajaba a la costa sin carga se ofreció a llevarlos, vehículo incluido.

Los esfuerzos de Eduardo, Mónica y Patricio en beneficio de la conservación del patrimonio cultural de Chile deberían ser relevados y objeto de un homenaje adicional.

Quizá lo más importante de Patricio sea la construcción de una vida plena de coherencia, fiel a sus principios y comprometido con el legado prehispánico y las poblaciones originales de este país. 